\title{
Các nhân tố tác động đến nợ xấu tại các ngân hàng thương mại Việt Nam
}

\section{Factors affecting non-performing loan of commercial banks in Vietnam}

\author{
Nguyễn Thị Như Quỳnh ${ }^{1 *}$, Lê Đình Luân ${ }^{1}$, Lê Thị Hương Mai ${ }^{1}$ \\ ${ }^{1}$ Trường Đại học Ngân hàng Thành phố Hồ Chí Minh, Việt Nam \\ "Tác giả liên hệ, Email: quynhntn@buh.edu.vn
}

\section{THÔNG TIN}

DOI: $10.46223 / \mathrm{HCMCOUJS.}$ econ.vi.13.3.524.2018

Ngày nhận: 07/06/2018

Ngày nhận lại: 10/07/2018

Duyệt đăng: 11/07/2018

Tù khóa:

FGLS, ngân hàng thương mại, nợ xấu

\section{TÓM TẮT}

Bài viết nhằm phân tích các nhân tố tác động đến nợ xấu của Ngân hàng thương mại (NHTM) trong giai đoạn 2006-2016, thông qua mẫu nghiên cứu gồm 25 NHTM cổ phần tại Việt Nam. Nhóm tác giả sử dụng mô hình Pooled OLS, FEM, REM sau đó lựa chọn mô hình phù hợp là FEM. Các kiểm định khuyết tật của mô hình lần lượt được tiến hành, phát hiện mô hình FEM có hiện tượng phương sai thay đổi. Để khắc phục tình trạng này, nhóm tác giả sử dụng mô hình hồi quy theo phương pháp bình phương tối thiểu tổng quát khả thi (Feasible Generalized Least Squares FGLS) để đảm bảo hiệu quả của mô hình. Kết quả nghiên cứu cho thấy với mức ý nghĩa thống kê $1 \%$, tốc độ tăng trưởng kinh tế, tăng trưởng tín dụng của ngân hàng và tỷ lệ thất nghiệp tác động ngược chiều với tỷ lệ nợ xấu. Đồng thời, tỷ lệ lạm phát và tỷ lệ nợ xấu năm trước tương quan thuận chiều với tỷ lệ nợ xấu hiện tại. Tuy nhiên, mối quan hệ giữa yếu tố quy mô và khả năng sinh lời của ngân hàng với tỷ lệ nợ xấu chưa được tìm thấy.

\begin{abstract}
The primary objective of this study was to explore the impact of factors on non-performing loan (NPL) of commercial banks in Vietnam over the period 2006-2016, using data for 25 commercial banks in Vietnam. The study used the Pooled OLS, FEM, REM and then chose the appropriate FEM model. The defect tests of the model were carried out, detecting the FEM model with heteroskedasticity phenomena. To overcome this situation, the study used the Feasible Generalized Least Squares (FGLS) regression model to ensure the effectiveness of the model. These results of empirical research revealed that with statistically significant $1 \%$, economic growth rate, credit growth
\end{abstract}


Keywords:

FGLS, commercial banks, non-performing loan

of the bank and the unemployment rate have a negative impact on the NPLs ratio. And the inflation and the NPLs ratio in the previous year are positively correlated with the NPLs ratio. However, the relationship between bank size and ROE with the NPLs ratios has not been found.

\section{Giới thiệu}

Nền kinh tế của một quốc gia sẽ không phát triển bền vững nếu hệ thống tài chính của quốc gia đó hoạt động kém hiệu quả và không ổn định (Badar, Javid, \& Zulfiquar, 2013). Hoạt động của ngân hàng đóng vai trò quan trọng trong việc duy trì ổn định hệ thống tài chính, tuy nhiên bản chất của hoạt động ngân hàng chứa đựng nhiều rủi ro. Một trong những tiêu chí để đo lường mức độ rủi ro của ngân hàng là chỉ tiêu nợ xấu. Theo số liệu của báo cáo tài chính (BCTC) các ngân hàng, trong giai đoạn 2006-2012, tỷ lệ nợ xấu tăng gấp đôi từ 2\% năm 2006 đến $4.08 \%$ năm 2012, nhưng tới năm 2016 tỷ lệ này còn $2.52 \%$ (giảm $1.56 \%$ ).

ĐVT: tỷ đồng, \%

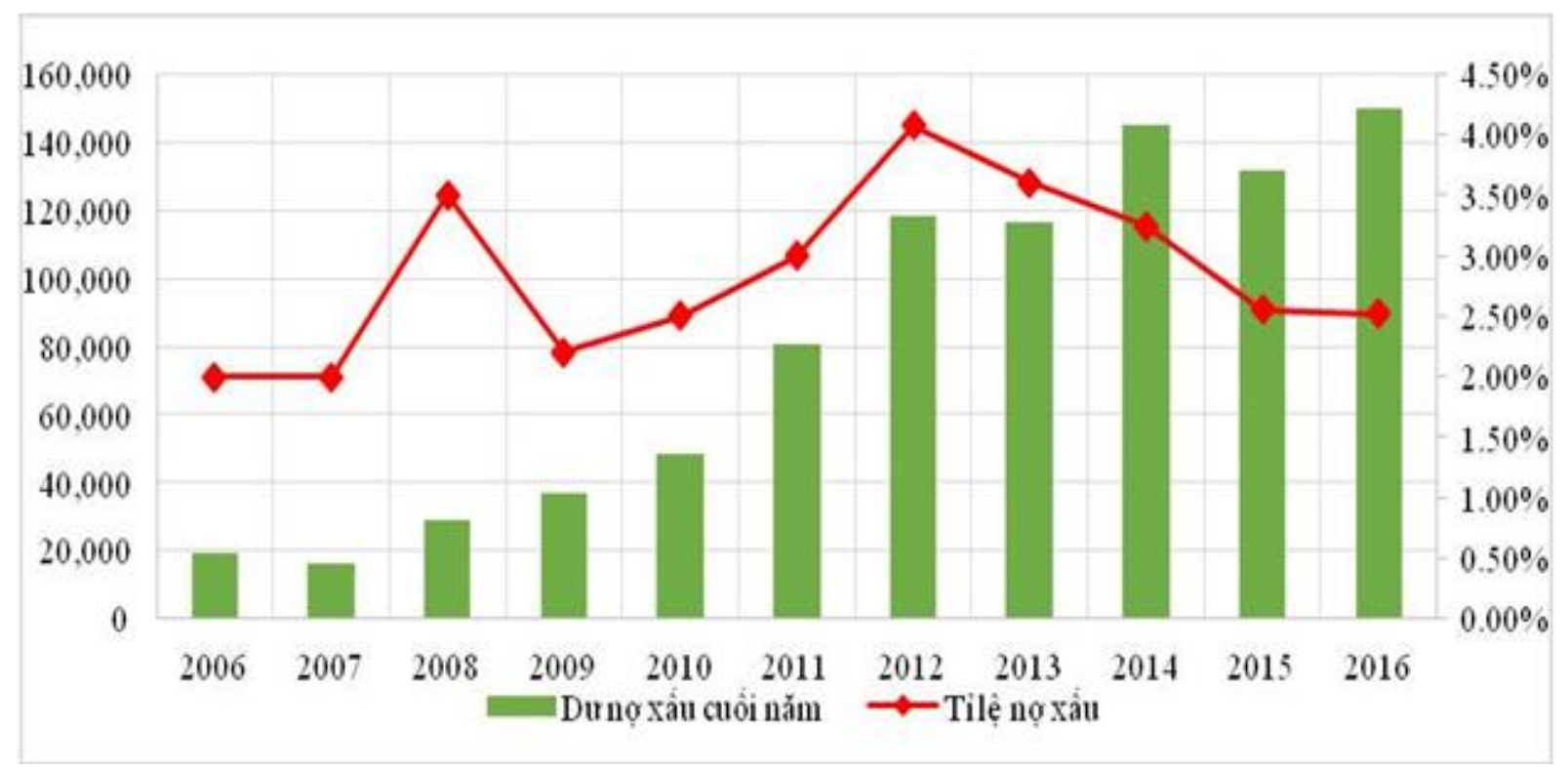

Hình 1. Nợ xấu hệ thống ngân hàng TMCP Việt Nam giai đoạn 2006 - 2016

Nguồn: Nhóm tác giả tự tổng hợp từ Báo cáo thường niên và sbv.gov.vn

Việc nghiên cứu và tìm ra các nhân tố tác động đến nợ xấu đối với NHTM sẽ giúp cho nhà quản trị ngân hàng chủ động hơn trong quá trình khắc phục, thay đổi và tìm ra chính sách phù hợp để giảm thiểu nợ xấu. Ngoài ra việc xác định các yếu tố này cũng sẽ giúp cho NHNN có chính sách phù hợp trong quá trình tái cấu trúc hệ thống ngân hàng. Bài viết sẽ phân tích các nhân tố tác động đến nợ xấu của NHTM. Phần tiếp theo của bài viết sẽ nghiên cứu về cơ sở lý thuyết và các nhân tố tác động đến nợ xấu, phần 3 là phương pháp, mô hình và dữ liệu nghiên cứu, phần 4 kết quả nghiên cứu và thảo luận, phần 5 kết luận và khuyến nghị một số chính sách. 


\section{Cơ sở lý thuyết và các nhân tố tác động đến nọ̣ xấu}

\subsection{Cơ sở lý thuyết}

Nợ xấu là thuật ngữ được sử dụng phổ biến trên thế giới với các từ như "Non-performing loans" (NPL), "bad debt”, "doubtful debt" chỉ các khoản nợ khó đòi (Fofack, 2005) hoặc các khoản vay có vấn đề (Berger \& De Young, 1997) hoặc khoản nợ không trả được (defaulted loans) mà ngân hàng không thể thu lợi từ nó (Ernst \& Young, 2004) hay các khoản cho vay bắt đầu được đưa vào nợ xấu khi đã quá hạn trả nợ gốc và lãi 90 ngày trở lên (Rose, 2004). Hiện tại không có một quy tắc hay chuẩn mực thống nhất khi thảo luận về vấn đề nợ xấu.

Tại Việt Nam, theo quan điểm của NHNN, nợ xấu được định nghĩa là những khoản nợ được phân loại vào nhóm nợ dưới tiêu chuẩn, nợ nghi ngờ và nợ có khả năng mất vốn. Trong đó, nợ xấu được phân loại theo hai tiêu chí là định lượng và định tính. Về định lượng, nợ nhóm 3 là các khoản nợ quá hạn từ 90 ngày đến 180 ngày; nợ nhóm 4 là các khoản nợ quá hạn từ 181 ngày đến 360 ngày và nợ nhóm 5 là các khoản nợ quá hạn trên 360 ngày. Trong khi đó theo định tính, nợ xấu là các khoản nợ dưới chuẩn, bị nghi ngờ về khả năng trả nợ lẫn khả năng thu hồi vốn của chủ nợ (Dinh, 2012; N. T. Nguyen, 2013).

Do các yếu tố định tính khó xác định nên nợ xấu trong bài nghiên cứu sẽ được thu thập theo tiêu chí định lượng:

$$
\text { Tỷ lệ nợ xấu }=\frac{\text { Dư nợ nhóm 3+Dư nợ nhóm 4+Dư nợ nhóm } 5}{\text { Tổng dư nợ }}
$$

\subsection{Các nhân tố tác động đến nọ xấu của NHTM}

Hiện nay, trên thế giới và tại Việt Nam có nhiều nghiên cứu thực nghiệm và các giả thuyết bàn về các nhân tố tác động đến nợ xấu của NHTM.

\section{Các nhân tố vi mô thuộc đặc thù ngân hàng Quy mô ngân hàng}

Quy mô thể hiện năng lực thị trường của ngân hàng đó. Hầu hết các kết quả nghiên cứu theo nhóm tác giả thống kê thì yếu tố quy mô ngân hàng tác động cùng chiều đến tỷ lệ nợ xấu. Cụ thể, có thể kể đến nghiên cứu của Rajan và Dhal (2003), Ghosh (2015), Do và Nguyen (2013), V. T. H. Nguyen (2015), K. T. Nguyen và Dinh (2015).

Trong khi đó, tương quan nghịch chiều giữa quy mô và nợ xấu cũng được tìm thấy trong nghiên cứu của Salas và Suarina (2002). Thật vậy, ngân hàng có tổng tài sản lớn thể hiện quy mô ngân hàng lớn. Quy mô ngân hàng lớn cho phép các NHTM có điều kiện để đầu tư cải thiện quy trình tín dụng, chất lượng quản trị rủi ro cũng như nguồn nhân lực chất lượng cao. Mặt khác, quy mô lớn cùng với thị phần cao cho phép các NHTM có thể đa dạng hóa hoạt động tín dụng của mình, từ đó giúp giảm thiểu rủi ro tập trung tín dụng (Louzis, Vouldis, \& Metaxas, 2010).

\section{Tăng trưởng tín dụng}

Tăng trưởng tín dụng thể hiện quy mô vốn cung ứng ra nền kinh tế, các nghiên cứu phân tích tác động của tăng trưởng tín dụng đến tỷ lệ nợ xấu cho các kết quả không thống nhất. Một phần các nghiên cứu trước chỉ ra rằng tỷ lệ nợ quá hạn và nợ xấu có liên quan đến tốc độ tăng trưởng tín dụng nhanh chóng. Salas và Saurina (2002) đã nghiên cứu các ngân hàng Tây Ban 
Nha thấy rằng tăng trưởng dư nợ cho vay có liên quan đến khoản vay không có khả năng thanh toán. Weinberg (1995) đưa ra giả thuyết rủi ro cho vay tăng trong thời kỳ phát triển kinh tế vì lợi nhuận kỳ vọng từ các dự án đầu tư được cải thiện và do đó, lợi nhuận kỳ vọng từ tất cả các khoản vay đã khiến ngân hàng thường xuyên nới lỏng các tiêu chuẩn bảo lãnh phát hành, trong khi hoạt động tín dụng cần được thắt chặt các tiêu chuẩn, do đó các khoản nợ xấu tăng lên cùng với sự gia tăng tín dụng. Ngoài ra, các kết quả nghiên cứu của Klein (2013), Do và Nguyen (2013) và V. T. H. Nguyen (2015) cũng đồng quan điểm trên.

Trong khi đó, nghiên cứu của Nguyễn Tuấn Kiệt và Đinh Hùng Phú (2016) lại cho rằng tốc độ tăng trưởng tín dụng tương quan nghịch chiều với nợ xấu. Điều này được lý giải là trong giai đoạn nghiên cứu ở Việt Nam các khoản tín dụng của các ngân hàng thường sau một năm mới phát sinh nợ xấu, nghĩa là nếu năm nay ngân hàng tăng trưởng tín dụng thấp vì năm trước ngân hàng có tỷ lệ nợ xấu cao, nên ngân hàng bắt buộc tập trung xử lý nợ xấu kèm theo việc hạn chế tăng trưởng tín dụng do áp đặt của NHNN.

\section{Khả năng sinh lời của ngân hàng}

Hầu hết các nghiên cứu thực nghiệm đã chỉ ra nợ xấu và khả năng sinh lời của ngân hàng có quan hệ ngược chiều như nghiên cứu của Klein (2013), Ghosh (2015), Le và Mai (2015), K. T. Nguyen và Dinh (2016).

Thật vậy, một ngân hàng có khả năng sinh lời cao sẽ có ít động cơ tham gia vào các hoạt động cấp tín dụng với rủi ro cao. Ngược lại, những ngân hàng hoạt động kém hiệu quả sẽ cố gắng sinh lời bằng việc cấp các khoản tín dụng không đạt chuẩn, do đó tại các ngân hàng này dễ dàng nảy sinh các khoản nợ xấu hơn. Vấn đề này cũng hợp lý khi lợi nhuận các ngân hàng Việt Nam thu được chủ yếu từ hoạt động tín dụng, vì vậy, khi lợi nhuận cao, chất lượng các khoản vay của các ngân hàng tốt, vốn và lãi được thu hồi đầy đủ, dẫn đến nợ xấu thấp (K. $T$. Nguyen \& Dinh, 2016).

\section{Tỷ lệ nọ̣ xấu năm trước}

Theo Makri, Tsagkanos, và Bellas (2014), việc thu hồi nợ không hiệu quả là nguyên nhân tăng nợ xấu cũng như những khó khăn gặp phải khi xử lý các khoản nợ xấu. Thêm vào đó, các khoản nợ xấu tồn đọng các năm trước đến hiện tại chưa được giải quyết triệt để thì sẽ làm tăng nợ xấu trong năm hiện tại.

\section{Nhân tố vĩ mô:}

\section{Tốc độ tăng trưởng kinh tế}

Các nghiên cứu khi xem xét tác động của các nhân tố vĩ mô đến nợ xấu đều khẳng định ảnh hưởng của tăng trưởng kinh tế đến chất lượng khoản vay. Các nghiên cứu trước đây hầu hết đều cho kết quả ngược chiều trong mối quan hệ này như Salas và Suarina (2002), Filip (2015), Ghosh (2015), Do và Nguyen (2013), V. T. H. Nguyen (2015), K. T. Nguyen và Dinh (2016), ... Nền kinh tế tăng trưởng tốt sẽ thúc đẩy hoạt động sản xuất, kinh doanh được thuận lợi, từ đó nâng cao khả năng thanh toán các khoản vay của người đi vay (Klein, 2013; Makri et al., 2014). 


\section{Tỷ lệ thất nghiệp}

Makri và cộng sự (2014) khi sử dụng phương pháp hồi quy với mẫu 14 trong số 17 quốc gia thuộc khu vực đồng Euro, kết quả cho thấy có mối quan hệ rõ ràng giữa tỷ lệ thất nghiệp và nợ xấu, nợ xấu tăng lên do sự tăng trưởng của tỷ lệ thất nghiệp. Filip (2015), Ghosh (2015), ... cũng đồng quan điểm trên.

Khi thất nghiệp xảy ra, thu nhập của người đi vay sẽ giảm, do đó khả năng hoàn trả nợ gốc cũng như lãi vay của họ sẽ giảm, điều này dẫn đến tỷ lệ nợ xấu của ngân hàng sẽ tăng lên (Filip, 2015).

\section{Lạm phát}

Khi lạm phát tăng, người tiêu dùng giảm nhu cầu chi tiêu khiến hàng hóa tiêu thụ thấp, doanh nghiệp gặp khó khăn do hoạt động kinh doanh trì trệ, dẫn đến lợi nhuận thấp hơn kỳ vọng, thậm chí có thể xảy ra tình trạng thua lỗ làm ảnh hưởng đến khả năng trả nợ của doanh nghiệp, điều này khiến cho nợ xấu NHTM tăng lên (Filip, 2015; Do \& Nguyen, 2013; K. T. Nguyen \& Dinh, 2016).

\section{Phương pháp nghiên cứu}

\subsection{Mô hình nghiên cúu}

Dựa trên mô hình nghiên cứu của Salas và Saurina (2002), Klein (2013), V. T. H. Nguyen (2015), K. T. Nguyen và Dinh (2016), .. nhóm tác giả tiếp cận nghiên cứu theo phương pháp dữ liệu bảng năng động để giải thích sự tồn tại yếu tố thời gian trong tỷ lệ nợ xấu.

Mô hình có dạng:

$$
\mathrm{NPL}_{\mathrm{it}}=\propto N P L_{\mathrm{it}-1}+\beta(L) X_{\mathrm{it}}+\gamma M_{\mathrm{it}}+\varepsilon_{\mathrm{it}},,|\propto|<1, i=1, \ldots, n
$$

Trong đó:

- $\mathrm{i}$ và $\mathrm{t}$ biểu thị đường chéo và chiều thời gian trong mẫu dữ liệu bảng tương ứng, NPL $\mathrm{L}_{\mathrm{it}}$ là biến phụ thuộc, được xác định bằng logarit của tỷ lệ nợ xấu ngân hàng thứ i trong năm $\mathrm{t}$.

- Biến phụ thuộc NPL $L_{i t}$ được giải thích bởi độ trễ của nó là NPLit-1; $\beta(L)$ biểu thị độ trễ vector đa thức. $X_{i t}$ là vector của biến các yếu tố vi mô đặc thù của ngân hàng (ngoài biến nợ xấu trong quá khứ) bao gồm: khả năng sinh lời ( $\mathrm{ROE}_{\mathrm{it}}$ ), tỷ lệ tăng trưởng tín dụng (CREDIT $\mathrm{it}$ ), quy mô ngân hàng $\left(\mathrm{SIZE}_{\mathrm{it}}\right)$. Các biến này cũng được lấy giá trị logarit tự nhiên.

- $\mathrm{M}_{\mathrm{it}}$ là các biến các yếu tố vĩ mô gồm: tỷ lệ lạm phát ( $\mathrm{INF}_{\mathrm{i}}$ ), tốc độ tăng trưởng kinh tế (GDP $\left.{ }_{i t}\right)$, tỷ lệ thất nghiệp (UNTit).

- $\varepsilon_{\text {it: }}$ các sai số

Như vậy, dựa vào các nghiên cứu trước và thực tiễn tại Việt Nam về mối quan hệ giữa các nhân tố tác động tới nợ xấu NHTM, nhóm tác giả sử dụng các biến và dấu kỳ vọng trong mô hình nghiên cứu như sau (Bảng 1). 


\section{Bảng 1}

Các biến được sử dụng trong mô hình nghiên cứu

\begin{tabular}{|c|c|c|c|}
\hline Tên biến & Mô tả biến & $\begin{array}{c}\text { Dấu kì } \\
\text { vọng }\end{array}$ & Nghiên cứu trước \\
\hline $\begin{array}{l}\text { Tốc độ tăng } \\
\text { trưởng }\left(\mathrm{GDP}_{\mathrm{it}}\right)\end{array}$ & $\begin{array}{l}\text { Tốc độ tăng } \\
\text { trưởng kinh } \\
\text { tế }\end{array}$ & - & $\begin{array}{l}\text { Salas và Suarina (2002), Klein (2013), Makri } \\
\text { và cộng sự (2014), Filip (2015), Ghosh } \\
\text { (2015), Do và Nguyen (2013), V. T. H. } \\
\text { Nguyen (2015), K. T. Nguyen và Dinh } \\
\text { (2016) }\end{array}$ \\
\hline $\begin{array}{l}\text { Tỷ lệ thất nghiệp } \\
\left(\mathrm{UNT}_{\mathrm{it}}\right)\end{array}$ & $\begin{array}{l}\text { Tỷ lệ thất } \\
\text { nghiệp }\end{array}$ & + & $\begin{array}{l}\text { Klein (2013), Filip (2015), Ghosh (2015), } \\
\text { Makri và cộng sự (2014) }\end{array}$ \\
\hline $\begin{array}{l}\text { Tỷ lệ lạm phát } \\
\left(\mathrm{INF}_{\mathrm{it}}\right)\end{array}$ & $\begin{array}{l}\text { Tỷ lệ lạm } \\
\text { phát }\end{array}$ & + & $\begin{array}{l}\text { Klein (2013), Filip (2015), Ghosh (2015), } \\
\text { Do và Nguyen (2013) }\end{array}$ \\
\hline $\begin{array}{l}\text { Tỷ lệ nợ xấu } \\
\text { năm trước } \\
\left(\mathrm{NPL}_{\mathrm{i}(\mathrm{t}-1)}\right)\end{array}$ & $\begin{array}{c}\ln \\
\left(\frac{N o^{\prime} x a ̂ ́ u}{\text { Tổng } d \text { ư } n o^{\prime}}\right)\end{array}$ & + & $\begin{array}{l}\text { Beck, Jakubik, và Piloiu (2013), Do và } \\
\text { Nguyen (2013), V. T. H. Nguyen (2015) }\end{array}$ \\
\hline $\begin{array}{l}\text { Quy mô ngân } \\
\left.\text { hàng (SIZE }{ }_{i t}\right)\end{array}$ & $\begin{array}{l}\ln (\text { Tổng tài } \\
\text { sản })\end{array}$ & - & $\begin{array}{l}\text { Ghosh (2015), Do và Nguyen (2013), V. T. } \\
\text { H. Nguyen (2015), K. T. Nguyen và Dinh } \\
\text { (2015) }\end{array}$ \\
\hline $\begin{array}{l}\text { Tăng trưởng tín } \\
\text { dụng của ngân } \\
\left.\text { hàng (CREDIT }{ }_{\text {it }}\right)\end{array}$ & $\begin{array}{l}\text { Ln( dư nợit - } \\
\text { dư nợit-1) } / \text { dư } \\
\text { nợit-1 }\end{array}$ & + & $\begin{array}{l}\text { Keeton (1999), Klein (2013), Vithessonthi } \\
\text { (2016), Do và Nguyen (2013), V. T. H. } \\
\text { Nguyen (2015), Le và Mai (2015) }\end{array}$ \\
\hline $\begin{array}{l}\text { Khả năng sinh } \\
\text { lời của ngân } \\
\left.\text { hàng ( } \mathrm{ROE}_{\mathrm{it}}\right)\end{array}$ & $\begin{array}{c}\text { Ln (lợi } \\
\text { nhuận sau } \\
\text { thuế / VCSH } \\
\text { bình quân) }\end{array}$ & - & $\begin{array}{l}\text { Klein (2013), Ghosh (2015), Le và Mai } \\
\text { (2015), V. T. H. Nguyen (2015), K. T. } \\
\text { Nguyen và Dinh (2016) }\end{array}$ \\
\hline
\end{tabular}

Nguồn: Tác giả tổng hợp 


\subsection{Dũ liệu nghiên cúu}

Đối với các dữ liệu vi mô từ ngân hàng: Nghiên cứu thu thập dữ liệu từ báo cáo tài chính của 25 NHTMCP Việt Nam (bao gồm ACB, ABB, VietCapitalBank, LPB, Vietinbank, BIDV, DongA bank, Seabank, KLB, Maritime bank, Techcombank, NamABank, Vietcombank, HDBank, OCB, MB Bank, VIB, NCB, Saigonbank, SHB, Sacombank, VietABank, VP Bank, PG Bank, Eximbank) trong giai đoạn 2006 - 2016. Lý do nghiên cứu chỉ sử dụng dữ liệu của 25 ngân hàng này trong giai đoạn được đề cập vì trong giai đoạn này chỉ có 25 NHTMCP công bố đủ dữ liệu mà bài viết cần. Các ngân hàng được chọn đáp ứng tiêu chí còn tồn tại và hoạt động cho tới hết năm 2016.

Các dữ liệu vĩ mô bao gồm tăng trưởng kinh tế, tỷ lệ lạm phát, tỷ lệ thất nghiệp được nhóm tác giả thu thập từ Worldbank, IMF.

Kết quả thống kê mô tả cho các biến được sử dụng trong nghiên cứu được thể hiện trong Bảng 2 .

\section{Bảng 2}

Thống kê mô tả các biến trong mô hình

\begin{tabular}{|l|c|c|c|c|c|}
\hline \multicolumn{1}{|c|}{ Biến } & $\begin{array}{c}\text { Số quan } \\
\text { sát }\end{array}$ & Trung bình & Độ lệch chuẩn & $\begin{array}{c}\text { Giá trị nhỏ } \\
\text { nhất }\end{array}$ & $\begin{array}{c}\text { Giá trị lớn } \\
\text { nhất }\end{array}$ \\
\hline $\mathrm{NPL}_{\mathrm{it}}$ & 269 & -3.980146 & 0.764859 & -7.130899 & 0.5988365 \\
\hline $\mathrm{GDP}_{\mathrm{it}}$ & 275 & 0.0612455 & 0.0061772 & 0.0525 & 0.0713 \\
\hline $\mathrm{INF}_{\mathrm{it}}$ & 275 & 0.0915382 & 0.0709486 & -0.019079 & 0.2267332 \\
\hline $\mathrm{UNT}_{\mathrm{it}}$ & 275 & 0.0220909 & 0.0026143 & 0.018 & 0.026 \\
\hline $\mathrm{ROE}_{\mathrm{it}}$ & 271 & -2.543055 & 1.090763 & -7.26443 & 2.609334 \\
\hline $\mathrm{CREDIT}_{\mathrm{it}}$ & 247 & -1.26966 & 1.198215 & -9.21034 & 2.2428583 \\
\hline $\mathrm{SIZE}_{\mathrm{it}}$ & 271 & 2.371843 & 0.1332445 & 1.904761 & 2.626271 \\
\hline
\end{tabular}

Nguồn: Kết xuất từ phần mềm Stata 13

\section{Kết quả nghiên cứu và thảo luận}

Bảng 3 cho thấy, NPLit không có đa cộng tuyến nghiêm trọng với các biến số độc lập do hệ số tương quan đều nhỏ hơn 0.8 (Farrar \& Glauber, 1967). 


\section{Bảng 3}

Ma trận tương quan các biến trong mô hình nghiên cứu

\begin{tabular}{|c|c|c|c|c|c|c|c|c|}
\hline Biến & NPL $_{i t}$ & NPLit-1 & GDP $_{i t}$ & $\mathbf{I N F}_{\text {it }}$ & $\mathbf{U N T}_{\text {it }}$ & $\begin{array}{c}\text { CREDIT } \\
\text { it }\end{array}$ & ROE $_{i t}$ & $\underset{t}{\text { SIZE }_{i}}$ \\
\hline NPL $_{i t}$ & 1.000 & & & & & & & \\
\hline NPL $_{i t-1}$ & 0.4806 & 1.000 & & & & & & \\
\hline GDPit & -0.3074 & -0.1403 & 1.000 & & & & & \\
\hline INF $_{\text {it }}$ & -0.0254 & -0.3186 & -0.0906 & 1.000 & & & & \\
\hline $\mathbf{U N T}_{\mathbf{i t}}$ & -0.3007 & -0.1639 & 0.2405 & 0.0886 & 1.000 & & & \\
\hline $\begin{array}{c}\text { CREDI } \\
\mathbf{T}_{\text {it }} \\
\end{array}$ & -0.2572 & -0.1497 & 0.3095 & 0.0884 & 0.4191 & 1.000 & & \\
\hline ROE $_{i t}$ & -0.2755 & -0.2230 & 0.1094 & 0.2341 & 0.2860 & 0.2949 & 1.000 & \\
\hline SIZE $_{\text {it }}$ & 0.0611 & 0.0897 & -0.0826 & -0.2721 & -0.2773 & -0.2419 & 0.1300 & 1.000 \\
\hline
\end{tabular}

Nguồn: Kết xuất từ phần mềm Stata 13

Bảng 4 thể hiện tổng hợp kết quả của mô hình Pooled OLS, FEM, REM khi tác giả thực hiện hồi quy. Kết quả Bảng 4 cho thấy, $\mathrm{R}^{2}$ lần lượt của POOLED OLS, REM, FEM là 35.45\%, $28.97 \%, 30.68 \%$. Điều này thể hiện rằng các biến độc lập được sử dụng trong mô hình có thể đã giải thích được 35.45\%,28.97\%, 30.68\% sự thay đổi trong tỷ lệ nợ xấu của các ngân hàng. Giá trị p-value của mô hình được ước lượng theo 3 phương pháp trên đều là 0.0000 - giá trị này nhỏ hơn $\alpha=0.01$. Như vậy, ước lượng của ba phương pháp này đều có ý nghĩa thống kê.

Tuy nhiên, việc ước lượng theo mô hình Pooled OLS không phản ánh được tác động riêng biệt, mang tính đặc thù của từng ngân hàng. Do đó, để khắc phục hạn chế này, nghiên cứu tiếp tục lựa chọn ước lượng mô hình hồi quy theo phương pháp tác động cố định FEM và tác động ngẫu nhiên REM. Kết quả hồi quy cho thấy kết quả mô hình REM có các thông số giống với mô hình Pooled OLS, còn mô hình FEM các biến trong mô hình đều cùng dấu với mô hình Pooled OLS và có ý nghĩa nhưng mức độ tác động và mức ý nghĩa lại có sự khác nhau ở 2 mô hình. Bên cạnh đó, ở mô hình FEM có thêm một biến có ý nghĩa ở mức 5\% là biến ROEit ngược dấu với tỷ lệ nợ xấu ngân hàng.

\section{Bảng 4}

Kết quả mô hình nghiên cứu POOLED OLS, FEM và REM

\begin{tabular}{|c|c|c|c|}
\hline Biến & POOLED OLS & REM & FEM \\
\hline \multirow{2}{*}{ GDP $_{\text {it }}$} & $-21.6495^{* * *}$ & $-21.6495^{* * *}$ & $-24.17823^{* * *}$ \\
& $(7.818448)$ & $(7.818448)$ & $(7.903077)$ \\
\hline
\end{tabular}




\begin{tabular}{|c|c|c|c|}
\hline Biến & POOLED OLS & REM & FEM \\
\hline $\mathrm{UNT}_{\text {it }}$ & $\begin{array}{c}-38.47075^{* * *} \\
(18.59383) \\
\end{array}$ & $\begin{array}{c}-38.47075^{* * *} \\
(18.59383) \\
\end{array}$ & $\begin{array}{l}-33.40755^{*} \\
(20.00597) \\
\end{array}$ \\
\hline $\mathrm{INF}_{\mathrm{it}}$ & $\begin{array}{c}1.617915^{*} \\
(0.6572823) \\
\end{array}$ & $\begin{array}{c}1.617915^{*} \\
(0.6572823)\end{array}$ & $\begin{array}{l}1.438222 * * \\
(0.7242406) \\
\end{array}$ \\
\hline NPLit-1 & $\begin{array}{c}0.4602879 * * * \\
(0.0624571)\end{array}$ & $\begin{array}{c}0.4602879 * * * \\
(0.0624571)\end{array}$ & $\begin{array}{l}0.29916^{* * * *} \\
(0.0733148)\end{array}$ \\
\hline SIZE $_{\text {it }}$ & $\begin{array}{c}0.1254202 \\
(0.4058038)\end{array}$ & $\begin{array}{c}0.1254202 \\
(0.4058038)\end{array}$ & $\begin{array}{c}1.204488 \\
(0.8821612) \\
\end{array}$ \\
\hline CREDIT $_{\text {it }}$ & $\begin{array}{l}-0.0314504 \\
(0.0415894)\end{array}$ & $\begin{array}{l}-0.0314504 \\
(0.0415894)\end{array}$ & $\begin{array}{l}-0.0277163 \\
(0.0495247)\end{array}$ \\
\hline $\mathrm{ROE}_{\mathrm{it}}$ & $\begin{array}{c}-1.1048886 \\
(0.468327) \\
\end{array}$ & $\begin{array}{c}-1.1048886 \\
(0.468327) \\
\end{array}$ & $\begin{array}{c}-0.1107841^{* *} \\
(0.0526507)\end{array}$ \\
\hline Cons & $\begin{array}{l}-0,7216739 \\
(1,304945) \\
\end{array}$ & $\begin{array}{l}-0,7216739 \\
(1,304945) \\
\end{array}$ & $\begin{array}{l}-3,898641 \\
(2,416071) \\
\end{array}$ \\
\hline Số quan sát & 218 & 218 & 218 \\
\hline & $F(7.210)=16.48$ & $\begin{array}{c}\text { Wald chi2(7) = } \\
115.33\end{array}$ & $F(7.186)=11.76$ \\
\hline & Prob $>F=0.0000$ & $\begin{array}{c}\text { Prob }>\text { chi } 2= \\
0.0000\end{array}$ & Prob $>F=0.0000$ \\
\hline & $\mathrm{R}^{2}=0.3545$ & $\mathrm{R}^{2}$ within $=0.2897$ & $\mathrm{R}^{2}$ within $=0.3068$ \\
\hline
\end{tabular}

*, **, *** tương ứng với mức ý nghĩa thống kê 10\%,5\%,1\%

Nguồn: Kết quả phân tích dữ liệu của nhóm nghiên cứu

Vì vậy, để xác định mô hình nào phù hợp hơn, nghiên cứu thực hiện kiểm định Hausman Test để chọn lựa giữa mô hình FEM và REM. Kiểm định cho kết quả p-value $=0.00138<\alpha=$ 0.05. Với mức ý nghĩa $1 \%$, ta bác bỏ giả thuyết H0, tức mô hình FEM được chọn. Như vậy, trong ba mô hình Pooled OLS, REM và FEM khi hồi quy dữ liệu bảng thì mô hình FEM là phù hợp nhất với tổng thể số liệu nghiên cứu các nhân tố tác động đến tỷ lệ nợ xấu tại các NHTM.

Kiểm định hiện tượng phương sai thay đổi: Để xem mô hình FEM có xảy ra hiện tượng phương sai thay đổi hay không, nhóm tác giả tiến hành kiểm định Wald để kiểm tra. Kết quả cho thấy giả thuyết $\mathrm{H} 0$ - phương sai đồng nhất bị bác bỏ (p-value $=0.0000<\alpha=0.05$ ) tức là có tồn tại hiện tượng phương sai thay đổi trong mô hình, với mức ý nghĩa 5\%. 
Như vậy, sau khi kiểm định, mô hình hồi quy nghiên cứu bị vi phạm hiện tượng phương sai không thay đổi. Do đó, nhóm tác giả thực hiện hồi quy theo phương pháp bình phương tổi thiểu tổng quát khả thi FGLS (Feasible Generalized Least Squares) nhằm kiểm soát hiện tượng này để tăng tính hiệu quả cao cho mô hình nghiên cứu. Bảng 5 là kết quả mô hình được xử lý vấn đề phương sai thay đổi:

\section{Bảng 5}

Kết quả ước lượng mô hình FGLS

\begin{tabular}{|l|c|c|c|}
\hline \multicolumn{1}{|c|}{ Biến } & Hệ số & Sai số chuẩn & P - value \\
\hline GDPit & -16.76133 & 3.756384 & 0.000 \\
\hline UNT $_{\text {it }}$ & -28.11477 & 8.794796 & 0.001 \\
\hline INF $_{\text {it }}$ & 1.876038 & 0.3110112 & 0.000 \\
\hline NPL $_{i t-1}$ & 0.5325985 & 0.0457227 & 0.000 \\
\hline SIZE $_{\text {it }}$ & 0.0204614 & 0.2034225 & 0.920 \\
\hline CREDIT $_{\text {it }}$ & -0.0801332 & 0.0248936 & 0.001 \\
\hline ROE $_{\text {it }}$ & -0.0443937 & 0.0254649 & 0.081 \\
\hline Cons & -0.6392588 & 0.6560633 & 0.330 \\
\hline
\end{tabular}

Nguồn: Tác giả tổng hợp

Dựa vào Bảng 5 , ta có kết quả hồi quy theo phương pháp FGLS như sau: p-value = $0.000<\alpha=0.01$. Do đó, mô hình hồi quy có ý nghĩa thống kê mạnh mẽ tại mức $1 \%$.

Tóm lại, mô hình nghiên cứu có phương trình như sau với mức ý nghĩa thống kê $1 \%$ :

$$
\begin{aligned}
\mathrm{NPL}_{\mathrm{it}}=0.5325985 \mathrm{NPL}_{\mathrm{it}-1}- & 0.0801332 \mathrm{CREDIT}_{\mathrm{it}}-16.76133 \mathrm{GDP}_{\mathrm{it}}+1.8760382 \mathrm{INF}_{\mathrm{it}} \\
& -28.11477 \mathrm{UNT}_{\mathrm{it}}
\end{aligned}
$$

\section{Thông qua mô hình nghiên cứu trên, ta thấy:}

Một là, tỷ lệ nợ xấu năm trước có mối tương quan thuận chiều với tỷ lệ nợ xấu năm hiện tại. Điều này cho thấy chất lượng tín dụng có xu hướng giảm ở năm trước sẽ kéo theo nợ xấu năm sau tăng và ngược lại. Kết quả này cũng phù hợp với các nghiên cứu trước như Salas và Saurina (2002), Klein (2013), Do và Nguyen (2013), V. T. H. Nguyen (2015), .. Nợ xấu trong quá khứ cao thể hiện khả năng quản trị rủi ro trong cho vay của ngân hàng kém dẫn đến nợ xấu gia tăng trong hiện tại. Một cú sốc với nợ xấu sẽ có ảnh hưởng lâu dài đối với hệ thống ngân hàng (V. T. H. Nguyen, 2015).

Hai là, tốc độ tăng trưởng tín dụng có mối quan hệ ngược chiều tỷ lệ nợ xấu. Nguyên nhân trong giai đoạn 2006 - 2016 tại Việt Nam, trải qua thời kỳ suy giảm do ảnh hưởng của khủng hoảng kinh tế thế giới năm 2008 và chỉ phục hồi những năm sau đó. Quan hệ ngược chiều này phù hợp với chiều phục hồi của nền kinh tế sau khủng hoảng. Môi trường vĩ mô từng 
bước ổn định, nợ xấu suy giảm theo thời gian, tăng trưởng tín dụng tăng lên trong nền kinh tế. Tăng trưởng tín dụng thể hiện sự tăng lên về nhu cầu của các khoản cho vay đối với các dự án hoạt động kinh doanh của nền kinh tế. Đồng thời, kết quả này cũng được lý giải bởi các khoản tín dụng của các NHTM thường phát sinh nợ xấu sau một năm. Nếu ngân hàng năm trước có tỷ lệ nợ xấu cao thì năm sau ngân hàng có tốc độ tăng trưởng tín dụng thấp vì ngân hàng bắt buộc phải tập trung xử lý nợ xấu và hạn chế tăng trưởng tín dụng bởi sự áp đặt của NHNN (K. T. Nguyen \& Dinh, 2016). Do đó, kết quả này có thể được xem là phù hợp.

Ba là, tăng trưởng kinh tế có tác động ngược chiều với tỷ lệ nợ xấu. Đây là biến có tác động mạnh trong mô hình nghiên cứu. Kết quả này đúng với kỳ vọng ban đầu của nhóm tác giả. Điều này cũng hoàn toàn phù hợp với thực tiễn tại Việt Nam, trong giai đoạn nghiên cứu, nhìn chung nợ xấu của các NHTM gia tăng từ năm 2009 trong khi tăng trưởng kinh tế giai đoạn 2009 - 2016 thấp hơn giai đoạn 2006 - 2008. Khi nền kinh tế tăng trưởng, thu nhập của cá nhân, hộ gia đình tăng sẽ khiến họ tiêu dùng nhiều hơn, tạo điều kiện cho các doanh nghiệp hoạt động có hiệu quả, thu nhập gia tăng và do đó khả năng thanh toán các khoản nợ dễ dàng hơn. Ngược lại, khi kinh tế kém phát triển, hoạt động sản xuất kinh doanh bị trì trệ khiến họ không có khả năng trả nợ, từ đó khiến tỷ lệ nợ xấu các ngân hàng gia tăng.

Bốn là, tỷ lệ lạm phát có tương quan thuận chiều với tỷ lệ nợ xấu. Khi tỷ lệ lạm phát trong nền kinh tế tăng cao, NHNN thực hiện chính sách tiền tệ thắt chặt để chống lạm phát, hoạt động tín dụng của các NHTM cũng sẽ bị ảnh hưởng. Cụ thể, lãi suất cho vay tăng lên, chi phí đầu vào của doanh nghiệp bị đẩy lên đã làm giảm hiệu quả kinh doanh của các doanh nghiệp vay vốn, từ đó ảnh hưởng trực tiếp đến khả năng trả nợ của họ đối với ngân hàng. Bên cạnh đó, ngân hàng siết chặt việc cho vay sẽ dẫn đến tình trạng nền kinh tế thiếu tính thanh khoản, hoạt động sản xuất kinh doanh bị trì trệ, các doanh nghiệp chiếm dụng vốn lẫn nhau, mất khả năng thanh toán, nhiều doanh nghiệp, nhất là các doanh nghiệp vừa và nhỏ đứng trước nguy cơ phá sản, đẩy gánh nặng nợ xấu về phía các ngân hàng.

Năm là, tỷ lệ thất nghiệp tương quan nghịch chiều với tỷ lệ nợ xấu. Điều này ngược dấu với kì vọng ban đầu của nhóm tác giả đưa ra cũng như một số nghiên cứu trước đây của các tác giả Messai và Jouini (2013), Klein (2013), Filip (2015), Ghosh (2015), Makri và cộng sự (2014). Câu hỏi đặt ra ở đây là liệu kết quả này có thể phù hợp với thực tế tại Việt Nam trong giai đoạn nghiên cứu hay không?

Thực tế tình hình nợ xấu của các NHTM và tỷ lệ thất nghiệp Việt Nam trong giai đoạn 2009 - 2013 và năm 2015 ủng hộ cho kết quả nghiên cứu này của nhóm tác giả. Mối tương quan nghịch chiều này có thể giải thích hai nguyên nhân như sau: một là, tỷ trọng cho vay cá nhân tiêu dùng trên tổng dư nợ tín dụng vẫn còn thấp; đồng thời tỷ lệ thất nghiệp ở Việt Nam thấp và không biến động nhiều. Do đó, về lý thuyết khi thất nghiệp tăng lên có thể dẫn đến gia tăng nợ xấu trong trường hợp số người thất nghiệp không có giao dịch tín dụng với ngân hàng ít thì nguy cơ rủi ro nợ xấu sẽ giảm xuống. Nguyên nhân thứ hai xuất phát từ đặc thù thị trường tại Việt Nam cho phép người lao động có thể sẵn sàng làm bất kỳ công việc nào tuy khác với chuyên môn do đó tỷ lệ thất nghiệp ở Việt Nam thấp so với các nước trên thế giới và rất ít biến động. Thất nghiệp dạng này gần với thất nghiệp tự nhiên của nền kinh tế. Như vậy, điều này có 
nghĩa là tỷ lệ thất nghiệp tăng giảm không giải thích cho sự thay đổi của nợ xấu mà có thể nợ xấu thay đổi đơn thuần do những yếu tố khác tác động như GDP và các yếu tố ngân hàng.

\section{Một số khuyến nghị}

Thông qua kết quả nghiên cứu đã được trình bày ở trên, để giảm thiểu tỷ lệ nợ xấu của NHTM, nhóm tác giả đưa ra một số kiến nghị sau:

\section{Đối với Ngân hàng Thương mại}

Thứ nhất, các ngân hàng cần đảm bảo tăng trưởng tín dụng bền vững thể hiện ở việc giám sát chặt trong khâu thẩm định, quyết định cấp tín dụng cũng như giám sát sau khi cấp tín dụng. Các ngân hàng cần tránh cấp tín dụng quá mức, hạ chuẩn cấp tín dụng; cần xây dựng và xác định rõ ràng khẩu vị rủi ro, từ đó chủ động xây dựng danh mục tín dụng với các tỷ trọng phân bố dự kiến và lựa chọn phương án thích hợp với mục tiêu lợi nhuận và khả năng chịu đựng tổn thất của ngân hàng.

Thứ hai, tỷ lệ nợ xấu năm trước có tác động mạnh thuận chiều đến nợ xấu năm hiện tại nên các ngân hàng cần chú trọng tăng cường khả năng quản trị rủi ro phù hợp với quy mô tổng tài sản không ngừng tăng lên theo thời gian. Nâng cấp cơ chế quản lý và kiểm soát rủi ro, học hỏi từ các ngân hàng nước ngoài để tiến hành phân tích tín dụng và giám sát khả năng trả nợ của người vay một cách hiệu quả. Tiếp tục xử lý nhanh chóng nợ đọng bằng cách bán tài sản đảm bảo; tích cực thu hồi nợ từ khách hàng; gia hạn nợ, cơ cấu lại khoản vay, đánh giá lại nợ; bán nợ cho công ty mua bán nợ hay sử dụng dự phòng rủi ro để xử lý.

Thứ $b a$, các yếu tố vĩ mô thực sự tác động đến hoạt động cấp tín dụng và khả năng trả nợ của khách hàng. Các biến vĩ mô thường nằm ngoài tầm kiểm soát của các ngân hàng thương mại. Do đó, các ngân hàng cần chủ động đối phó trước những thay đổi của nền kinh tế nhằm bảo toàn tài sản của mình. Trong các thuật toán đánh giá sức chịu đựng (Stress test), các ngân hàng cần quan tâm hơn đến các biến số vĩ mô. Điều này không những giúp các ngân hàng chủ động ứng phó với những cú sốc của nền kinh tế mà còn giúp các ngân hàng dự báo được các khoản trích lập dự phòng rủi ro. Từ đó, các ngân hàng có thể đưa ra các chiến lược phát triển hợp lý, vừa đảm bảo được khả năng sinh lời, vừa bảo toàn được các tài sản có của ngân hàng.

\section{Đối với Ngân hàng Nhà nước Việt Nam}

Do tốc độ tăng trưởng kinh tế GDP tăng thì tỷ lệ nợ xấu có xu hướng giảm, khả năng trả nợ của người đi vay tăng và ngược lại. Vì vậy, NHNN cần có các biện pháp kích cầu nền kinh tế, hỗ trợ cho khu vực kinh tế tư nhân trong sản xuất kinh doanh và tiếp cận vốn.

Đồng thời, trong từng thời kỳ nhất định, $\mathrm{NHNN}$ cần có một chính sách tiền tệ phù hợp nhằm kiểm soát lạm phát ở mức thấp, giúp giảm nợ xấu.

\section{Tài liệu tham khảo}

Badar, M., Javid, Y., \& Zulfiquar, S. (2013). Impact of macroeconomic forces on nonperforming loans: An empirical study of commercial banks in Pakistan. Wseas Transactions on Business and Economics, 56A(2013), 13807-13814. 
Beck, R., Jakubik, P., \& Piloiu, A. (2013). Non-performing loans: What matters in addition to the economic cycle? Retrieved March 10, 2018, from https://www.ecb.europa.eu//pub/pdf/scpwps/ecbwp1515.pdf

Berger, A., \& DeYoung, R. (1997). Problem loas and cost efficiency commercial banks. Journal of Banking and Finance, 21, 1-29.

Dinh, V. T. T. (2012). So sánh nợ xấu, phân loại nợ và trích lập dự phòng rủi ro tín dụng của Việt Nam và thông lệ quốc tế [Vietnam's NPLs comparison, debt classification and credit risk provisioning and international practices]. Tạp chí Công nghệ Ngân hàng, 19, 5-12.

Do, A. Q., \& Nguyen, H. D. (2013). Phân tích thực tiễn về nhũng yếu tố quyết định đến nợ xấu tại các ngân hàng thưong mại Việt Nam [Practical analysis of the determinants of bad debt in Vietnamese commercial banks]. Paper presented at Hội thảo khoa học: Seminar Nghiên cứu Kinh tế và Chính sách số 07 , Trung tâm Nghiên cứu Kinh tế và Chính sách tổ chức, Hanoi, Vietnam.

Ernst \& Young, LLP. (2004). The Ernst \& Young tax guide 2004. Hoboken, NY: John Wiley \& Sons.

Farrar, D., \& Glauber, R. (1967). Multicollinearity in regression analysis: The problem revisited. Review of Economics and Statistics, 49, 92-107.

Filip, B. F. (2015). The quality of bank loans within the framework of Globalization. Procedia Economics and Finance, 20, 208-217.

Fofack, H. (2005). Non-performig loans in sub-Saharan Africa: Causal analysis and macroecomic implications. Retrieved March 1, 2018, from https://papers.ssrn.com/sol3/papers.cfm?abstract_id=849405

Ghosh, A. (2015). Banking-industry specific and regional economic determinants of nonperforming loans: Evidence from US state. Journal of Financial Stability, 20, 93-104.

Keeton, W. R. (1999). Does faster loan growth lead to higher loan losses? Federal Reserve Bank of Kansas City. Economic Review, 84(2) 57-75.

Klein, N. (2003). Non-performing loan in CESEE: Determinants and impact on macroeconomic performance. Retrieved March 3, 2018, from https://www.imf.org//media/Websites/IMF/imported-full-text-pdf/external/pubs/ft/wp/2013/_wp1372.ashx

Le, A. H., \& Mai, T. P. T. (2015). Ảnh hưởng của các cú sốc kinh tế vĩ mô đến nợ xấu ở Việt Nam [The impact of macroeconomic shocks on bad debt in Vietnam]. Tạp chí Kinh tế và Dụ báo, 16, 81-84.

Louzis, D. P., Vouldis, A. T., \& Metaxas, V. L. (2010). Macroeconomic and bank-specific determinants of non-performing loans in Greece: A comparative study of mortgage, business and consumer loan portfolios. Journal of Banking and Finance, 36(4), 10121027.

Makri, V., Tsagkanos, A., \& Bellas, A. (2014). Determinants of non-performing loans: The case of Eurozone. Panoeconomicus, 2, 193-206. 
Messai, A. S., \& Jouini, F. (2013). Micro and macro determinants of non-performing loans. International Journal of Economics and Financial Issues, 3(4), 852-860.

Nguyen, K. T., \& Dinh, P. H. (2016). Các yếu tố vĩ mô và vi mô tác động đến nợ xấu của hệ thống ngân hàng Việt Nam [The macro and micro factors that affect the bad debt of the Vietnamese banking system]. Tạp chí Kinh tế và Phát triển, 229, 9-16.

Nguyen, N. T. (2013). Vấn đề xử lý nợ xấu tại các ngân hàng thuơng mại Việt Nam [The problem of dealing with bad debts in Vietnamese commercial banks]. Retrieved March 4, 2018, from http://hvnh.edu.vn/tapchi/vi/nam-2013/van-de-xu-ly-no-xau-tai-cac-nganhang-thuong-mai-viet-nam-61.html

Nguyen, V. T. H. (2015). Yếu tố tác động đến nợ xấu các ngân hàng thương mại Việt Nam [Factors affecting bad debts of commercial banks in Vietnam]. Tạp chí Phát triển kinh tế, 26(11), 80-98.

Rajan, R., \& Dahl, S. (2003). Non-performing loans and terms of credit od public sector banks in India: An empirical assessment. Occasional papers, Reserve Bank of India, 24, 82121.

Rose, P. (2004). Quản trị ngân hàng thuơng mại, Bản dịch Tiếng Việt [Commercial Banking Administration, Vietnamese translation]. Hanoi, Vietnam: NXB Tài chính.

Salas, V., \& Saurina, J. (2002). Credi risk in two institutional regimes: Spanish commercial and savings banks. Journal of Financial Services Research, 22(3), 203-224.

Vithessonthi, C. (2016). Deflation, bank credit growth, and non-performing loans: Evidence from Japan. International Review of Financial Analysis, 45, 295-305.

Weinberg, J. A. (1995). Cycles in lending standards. Federal Reserve Bank of Richmond Economic Quarterly, 81(3), 1-18. 